\title{
P 127 A RETROSPECTIVE REVIEW OF ANTIMICROBIAL PRESCRIBING AND INFECTION PREVALENCE IN A PALLIATIVE CARE UNIT
}

Jill McKane, Susan Addie, Mairi-clare McGowan. St Vincent's Hospice, Howwood, UK

10.1136/bmjspcare-2014-000654.168

Introduction Hospice patients are highly susceptible to infections of the urinary and respiratory tract. ${ }^{1} 234$ The use of antimicrobials for symptom control should be considered against the burden of treatment for the patient as well as antimicrobial resistance. $^{13} 5667$

The Scottish Antimicrobial Prescribing Group produce guidance and targets for hospital based empirical prescribing. The aim is to reduce clostridium difficile infection. ${ }^{7}$ Empirical prescribing standards state $95 \%$ of antimicrobials prescribed should be in line with local policy with rationale for use documented. ${ }^{7}$ These hospital targets are applicable to the hospice setting. ${ }^{8}$

Method A consecutive retrospective case note audit was completed for a four month period at St Vincent's Hospice in Howwood. An audit proforma with data collection parameters was developed during this process.

Results Thirty-three case notes were audited: $76.7 \%$ of patients received at least one course of antimicrobials during their admission. The main indications for antibiotics were urinary tract $(34 \%)$ and lower respiratory tract infections (60\%). Indications for prescribing were specified in $88 \%$ and duration specified in $68 \%$ of cases. Of these $38 \%$ completed the course, 35\% were continued longer and 26\% were discontinued early. Antimicrobial selection, dosing and route were in line with the Greater Glasgow and Clyde policy in $78 \%$ of prescriptions; however only 51\% also included documentation of duration. Of these prescriptions $91 \%$ were prescribed empirically without microbiology culture data.

Discussion The prevalence of infection rate, antibiotic use and improvement of symptom burden is variable within the literature. $\begin{array}{llllll}1 & 2 & 3 & 4 & 5\end{array}$ There is scope to improve practice surrounding antimicrobial initiation and documentation. Existing local guidelines are not specific to hospice care and should be adapted. We recommend and are working towards:

- Palliative Antimicrobial Guideline development and liaison with local antimicrobial stewards.

- Development of St Vincent's Hospice antimicrobial toolkit with inclusion of medical handover tools.

Re-audit and education.

\section{REFERENCES}

1 Raquel E, Reinbolt BS, Allison M, et al. Symptomatic treatment of infection in patients with advanced cancer receiving palliative care. J Pain Symptom Manage 2005; 175:175-182.

2 White $P$, Kuhlenschmidt $H$, Vanvura B, Navari RM. Antimicrobial use in patients with advanced cancer receiving hospice care. J Pain Symptom Manage 2003;25:438-43.

3 Pereira J, et al. A retrospective review of the frequency of infections and patterns of antibiotic utilization on a palliative care unit. J Pain Symptom Manage 1998;16:374-81.

4 Vitetta L, Kenner D, Sali A. Bacterial infections in terminally ill hospice patients. J Pain Symptom Manage 2000;20:326-334.

5 Clayton J, Fardell B, Hutton-Potts J, et al. Parental antibiotics in palliative care unit: prospective analysis of current practice. J Pall Med 2003;17:44-48.

6 Van der Steen J, Radbruch L, Hertogh CMPM. White paper defining optimal palliative care in older people with dementia: A Delphi study and recommendations from the European Association for Palliative Care. Pall Med Published Online First: 4 Jul 2013. doi:10.1177/0269216313493685

7 Scottish Government - Scottish Medicines Consortium - Scottish Antimicrobial Prescribing Group CDI HEAT Target (CEL April 2009) Hospital-based Empirical Prescribing National Report, April 2011.

8 Scottish Government - Scottish Medicines Consortium - Scottish Antimicrobial Prescribing Group Good Practice Recommendations for antimicrobial use in frail elderly patients in NHS Scotland, February 2013. 